\title{
Alexandre Duval-Stalla, Claude Monet - Georges Clemenceau: une histoire, deux caractères
}

Ida Merello

\section{(2) OpenEdition}

Journals

\section{Edizione digitale}

URL: http://journals.openedition.org/studifrancesi/5736

DOI: $10.4000 /$ studifrancesi.5736

ISSN: 2421-5856

\section{Editore}

Rosenberg \& Sellier

\section{Edizione cartacea}

Data di pubblicazione: 1 septembre 2011

Paginazione: 449

ISSN: 0039-2944

\section{Notizia bibliografica digitale}

Ida Merello, «Alexandre Duval-Stalla, Claude Monet - Georges Clemenceau: une histoire, deux caractères», Studi Francesi [Online], 164 (LV | II) | 2011, online dal 30 novembre 2015, consultato il 09 janvier 2021. URL: http://journals.openedition.org/studifrancesi/5736 ; DOI: https://doi.org/10.4000/studifrancesi. 5736

Questo documento è stato generato automaticamente il 9 janvier 2021.

\section{(c) (†)}

Studi Francesi è distribuita con Licenza Creative Commons Attribuzione - Non commerciale - Non opere derivate 4.0 Internazionale. 


\title{
Alexandre Duval-Stalla, Claude Monet - Georges Clemenceau: une histoire, deux caractères
}

\author{
Ida Merello
}

\section{NOTIZIA}

ALEXANDRE DUVAL-STALLA, Claude Monet - Georges Clemenceau: une histoire, deux caractères, Paris, Gallimard 2010, 296 pp.

1 L'A. ripercorre con minuziosa attenzione i diversi momenti della vita di Georges Clemenceau e Claude Monet, secondo «un montaggio» in parallelo delle due diverse carriere per poi mostrare la loro amicizia, indagata in tutta la sua ricchezza, e coglierne il ruolo nella creazione della serie delle Ninfee e nella decisione di farne dono allo Stato. L'A. segue tutte le incertezze di Monet, segnalando la funzione positiva di Clemenceau, anche quando non fu più direttamente coinvolto a livello di progetto ufficiale. Offre inoltre un prezioso sguardo d'assieme sia sull'uomo politico che sul pittore, proponendo in tal modo lo spaccato di un'epoca che ci fa riflettere sul peso e il ruolo che una società civile, in quanto tale, è felice di assegnare all'arte. 